\title{
РОЛЬ АУДИТА ЭФФЕКТИВНОСТИ В УЛУЧШЕНИИ ПОКАЗАТЕЛЕЙ ФИНАНСОВОЙ ДЕЯТЕЛЬНОСТИ КОММЕРЧЕСКИХ БАНКОВ
}

\section{THE ROLE OF PERFORMANCE AUDITS IN IMPROVING THE FINANCIAL PERFORMANCE OF COMMERCIAL BANKS}

Al-Saadi Mohanad Raheem Salim

Summary: Financial performance indicators of commercial banks Express the effectiveness of their functioning and, therefore, become one of the mandatory objects subject to performance audit. The results of the performance audit allow commercial banks to analyze their financial performance indicators in terms of profitability, liquidity and viability and develop ways to improve them. The financial performance of a commercial Bank is expressed in the final financial results (profit, loss, income and expenses), which are directly and indirectly related to each other. In the article, the author shows how information about credit risk and return on assets of a commercial Bank obtained as a result of an efficiency audit can affect the improvement of financial performance indicators of commercial banks and concludes that data on financial performance indicators and factors affecting such indicators identified in the framework of an efficiency audit not only help the decision-making process in a commercial Bank, but also allow us to focus on factors related to risk minimization and profit maximization.

Keywords: performance audit, commercial banks, financial performance indicators, risk management system, credit risk, return on assets, return on equity.

\author{
Аль-Саади Моханад Рахим Салим \\ Аспирант, ФГБОУ ВО «Российский экономический \\ университет имени Г.В. Плеханова» \\ mmhhdd39@yahoo.com
}

Аннотация: Показатели финансовой деятельности коммерческих банков выражают эффективность их функционирования, именно поэтому они становятся одним из обязательных объектов, подлежащих аудиту эффективности. Результаты аудита эффективности позволяют коммерческим банкам анализировать показатели своей финансовой деятельности с точки зрения прибыльности, ликвидности и жизнеспособности и вырабатывать направления по их улучшению. Эффективность финансовой деятельности коммерческого банка выражается в конечных финансовых результатах (прибыли, убытках, доходах и расходах), имеющих прямую и косвенную связь друг с другом. В статье автором показывается, каким образом информация о кредитном риске и рентабельности активов коммерческого банка, полученная в результате аудита эффективности, может влиять на улучшение показателей финансовой деятельности коммерческих банков. Делается вывод о том, что данные о показателях финансовой деятельности и факторах, влияющих на такие показатели, выявленные в рамках аудита эффективности, не только помогают процессу принятия решений в коммерческом банке, но и позволяют акцентировать внимание на факторах, связанных с минимизацией рисков, и максимизации прибыли.

Ключевые слова: аудит эффективности, коммерческие банки, показатели финансовой деятельности, система управления рисками, кредитный риск, рентабельность активов, рентабельность собственного капитала.

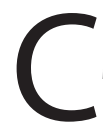

реди различных финансовых институтов современные коммерческие банки являются основным игроками на финансовых рынках. Банки стремятся к максимизации прибыли и несут ответственность за поддержание уровня минимального размера собственных средств (капитала) с одной стороны и повышения удовлетворенности клиентов с другой.

Для достижения поставленных целей в коммерческих банках существует система управления рисками, связанными с соответствием активов и пассивов, выданных кредитов и производными финансовыми инструментами. Основу системы управления рисками коммерческих банков составляет аудит эффективности, позволяющий коммерческим банкам анализировать и учитывать риски в целях улучшения показателей их финансовой деятельности.

В кредитных организациях аудит эффективности включает в себя целый комплекс мероприятий, направленных на проверку эффективности системы управления рисками (включая проверку полноты применения и эффективности методологии оценки банковских рисков и процедур управления банковскими рисками), а также эффективность структуры активов и пассивов [6].

Кредитный риск является одним из основных рисков, с которыми сталкивается коммерческий банк. Такой тип риска можно охарактеризовать как потенциальный убыток, возникающий в результате неисполнения контрагентом (заемщиком) своих обязательств в соответствии с договором, который он заключает с банком. Неисполнение обязательств заемщиком может возникнуть в силу различных причин, например, из-за его нежелания платить по кредиту или ухудшения его экономического состояния и т.д. Аудит эффективности позволяет осуществлять эффективное управление кредитным риском путем минимизации убытков коммерческих банков. На 
практике это реализуется за счет оценки рисков, связанных с портфелем активов банка, то есть качеством выданных банком кредитов.

Для измерения качества выданных кредитов в рамках аудита эффективности можно использовать несколько коэффициентов, однако наиболее доступным является измерение кредитного риска за счет соотношения «неработающих» (просроченных кредитов) к общей сумме кредитов. Такой коэффициент, как отмечается в специализированной литературе, показывает долю всех кредитов, которые были просрочены, но не списаны [3, с.72-75; 9]. После того, как платежи по кредиту были просрочены заемщиком, вероятность того, что кредит будет погашен в полном объеме, достаточно низка. Однако если должник снова начинает осуществлять платежи по просроченному кредиту, такой кредит становится реструктурируемым, даже если должник не погасил все пропущенные платежи.

Так или иначе ситуация с просроченными кредитами негативным образом сказывается на финансовых показателях деятельности коммерческих банков - чем выше доля просроченных кредитов в кредитном портфеле банка, тем ниже его качество, а значит, кредитная организация менее устойчива к негативным воздействиям макроэкономических факторов.

Получение информации по просроченным кредитам в рамках проведения аудита эффективности позволяет коммерческим банкам принимать меры по улучшению финансовых показателей и качеству кредитного портфеля. Так, например, коммерческие банки, имеющие в своих портфелях невозвратные и просроченные кредиты, могут объединять их в кредитные пулы и продать другим коммерческим банкам, чтобы избавиться от рискованных активов, влияющих на финансовые показатели.

Еще одним распространенным показателем эффективности деятельности коммерческого банка, который анализируется при проведении аудита эффективности, является рентабельность. Как правило, бухгалтерская прибыль - это разница между доходами и затратами. Рентабельность среди всех показателей финансовой деятельности считается наиболее сложным показателем с точки зрения концептуализации и измерения.

Показатели рентабельности коммерческого банка используются для оценки способности бизнеса генерировать прибыль в сравнении со всеми его расходами и другими соответствующими затратами в течение определенного периода времени [2]. В частности, эти коэффициенты указывают на прибыльность коммерческого банка после учета всех расходов и налогов на прибыль, эффективность операций, политику ценообразования, рентабельность активов и акционеров банка. Показатели рентабельности обычно считаются базовыми фи- нансовыми показателями, используемыми для оценки того, насколько хорошо банк работает с точки зрения прибыли. По большей части, если общий показатель рентабельности относительно выше по сравнению с конкурентами, средними показателями по отрасли или аналогичными показателями прошлых лет, то он принимается как показатель лучшей работы банка. Рентабельность коммерческого банка измеряется с использованием следующих трех критериев: рентабельность активов (ROA), рентабельность собственного капитала банка (ROE) и отношение затрат коммерческого банка к его доходу (C/I).

Рентабельность активов (ROA) определяется соотношением чистой прибыли к совокупным активам и показывает способность органов управления коммерческого банка приобретать депозиты по разумной цене и вкладывать их в прибыльные инвестиции. Этот коэффициент показывает, сколько чистого дохода генерируется на единицу активов. Рентабельность активов показывает рентабельность активов банка после всех расходов и налогов. Рентабельность активов коммерческого банка можно назвать также общим показателем эффективности управленческой деятельности банка, измеряющим сколько банком будет заработано после уплаты налогов за каждый рубль, вложенный в активы. То есть показатель рентабельности активов измеряет чистую прибыль на единицу данного актива, а также показывает, как банк может конвертировать свои активы в прибыль. Чем выше показатель рентабельности активов, тем лучше управленческая работа и эффективнее использование активов. И наоборот, низкий показатель рентабельности коммерческого банка, выявленный в рамках проведения аудита эффективности, позволит судить о неэффективном использовании активов и, как следствие, показывает необходимость улучшать финансовые показатели деятельности банка. Рентабельность активов может быть увеличена коммерческими банками либо за счет увеличения нормы прибыли, либо за счет увеличения оборота активов.

Следующий показатель финансовой деятельности коммерческого банка, влияющий на рентабельность банка, и который может быть улучшен по результатам аудита эффективности - это показатель рентабельности собственного капитала банка (ROE). Данный показатель рассчитывается как соотношение чистой прибыли к общему капиталу банка. С точки зрения значимости показатель рентабельности собственного капитала банка показывает такие важные параметры, как прибыльность банка и потенциал его роста. Показатель рентабельности собственного капитала банка - это норма доходности для акционеров или процент доходности на каждый рубль капитала, инвестированного в коммерческий банк после всех расходов и вычета всех налогов. Как и показатель рентабельности активов, показатель рентабельности собственного капитала позволяет эффективно 
измерять и качество управления в коммерческом банке. Чем выше показатель собственного капитала банка, тем эффективнее управление.

Однако не во всех случаях высокий показатель собственного капитала коммерческого банка положительно сказывается на финансовой деятельности коммерческого банка. Так, высокая рентабельность собственного капитала банка может быть обусловлена заемными средствами (финансовый рычаг) или более высокой рентабельностью активов. Финансовый рычаг создает важную разницу между рентабельностью активов и рентабельностью собственного капитала банка, поскольку финансовый рычаг всегда увеличивает собственный капитал. Такая динамика будет наблюдаться до тех пор, пока рентабельность активов банка выше процентной ставки по долгу. Исходя из сказанного, простой расчёт анализируемого показателя для принятия решений в области финансовой политики не достаточен. По мнению автора статьи, только отдельные факторы, выявленные при проведении аудита эффективности, могут позволить однозначно судить о том, положительное или отрицательное значение для финансовой политики банка имеет высокий показатель собственных средств.

Теперь акцентируем внимание на таком критерии рентабельности коммерческого банка, как отношение затрат к доходу (C/I). Данный критерий показывает соотношение общих затрат к общему доходу коммерческого банка и измеряет доход, полученный на единицу затрат.

Иными словами, отношение затрат к доходу позволяет коммерческому банку определить направление затрат и их объем для того, чтобы произвести конкретный банковский продукт. С точки зрения финансовой деятельности банка, чем выше отношение затрат к доходу, тем хуже показатели финансовой деятельности коммерческого банка и острее необходимость изменений.

Таким образом, можно говорит о том, что результаты аудита эффективности в части оценки показателей рентабельности коммерческого банка и факторов, влияющих на такие показатели, предоставляют коммерческим банкам ценный инструмент для измерения показателей их финансового состояния в сравнении с заранее определенными целями. Аудит эффективности показывает, насколько хорошо органы управления коммерческим банком используют совокупные активы или ресурсы для получения большего дохода (прибыли). Чем выше доходность, тем эффективнее банк использует свою базу активов. При этом речь идет обо всех активах коммерческого банка, включая те, которые возникают из обязательств перед кредиторами, а также те, которые возникают из взносов инвесторов.

Подводя итог, необходимо отметить, что аудит эффективности является наиболее действенными инструментом для анализа общих финансовых показателей деятельности коммерческого банка, направленным на оценку текущего финансового состояния и принятие решения об улучшении показателей финансовой деятельности. Данные о показателях финансовой деятельности и факторах, влияющих на такие показатели, выявленные в рамках аудита эффективности, не только помогают процессу принятия решений в коммерческом банке, но и позволяют акцентировать внимание на факторах, связанных с минимизацией рисков и максимизацией прибыли.

ЛИТЕРАТУРА

1. Федеральный закон от 02.12.1990 № 395-1 «0 банках и банковской деятельности» (с изм. и доп., вступ. в силу с 14.06.2020) // Собрание законодательства РФ. - 1996. - №6. - Ст. 492.

2. Будков Д.Ю. Инструментарий анализа эффективности деятельности банка // Международный журнал гуманитарных и естественных наук. - 2018. №5-2. - С.103-106.

3. Мадера А.Г. Оценка кредитоспособности потенциального заемщика // Международный журнал прикладных и фундаментальных исследований. 2013. - № 1. - С. 72-75.

4. Никифорова В.Д. Достаточность собственного капитала как основа регулирования банковских рисков в России//Научный журнал НИУ итМО. Серия: «Экономика и экологический менеджмент». - 2016. - № 1. - С. 40-46.

5. Никифорова В.Д., Коваленко А.В., Никифоров А.А. Теоретические и практические аспекты работы коммерческих банков с проблемными кредитами // Экономика и экологический менеджмент. - 2019. - №3. - С.93-100.

6. Тартарашвили Т.Т. Аудит эффективности управления рисками коммерческого банка // Международный бухгалтерский учет. - 2010. - №6. - С.43-49.

7. Хакимова Д.Л. Анализ просроченной задолженности по банковским кредитам в России // Молодой ученый. - 2014. - № 4. - С. 627-631.

8. Юсупова 0.А. 0 просроченной задолженности в кредитных портфелях российских банков, причинах ее возникновения и методах работы с ней // Финансы и кредит. - 2015. - №3 (627). - С.14-26.

9. ISLAM, MD AMINUL. An Analysis of the Financial Performance of National Bank Limited Using Financial Ratio. Journal of Behavioural Economics, Finance, Entrepreneurship, Accounting and Transport. - 2014. - №2 (5). - P. 121-129.

(с) Аль-Саади Моханад Рахим Салим (mmhhdd39@yahoo.com).

Журнал «Современная наука: актуальные проблемы теории и практики» 